\title{
Environmental Science
}

\section{Combination of large nanostructures and complex band structure for high performance thermoelectric lead telluride}

\author{
Yanzhong Pei, Nicholas A. Heinz, Aaron LaLonde and G. Jeffrey Snyder* \\ Received 9th June 2011, Accepted 11th July 2011 \\ DOI: 10.1039/c1ee01928g
}

\begin{abstract}
The complexity of the valence band structure in p-type $\mathrm{PbTe}$ has been shown to enable a significant enhancement of the average thermoelectric figure of merit $(z T)$ when heavily doped with $\mathrm{Na}$. It has also been shown that when $\mathrm{PbTe}$ is nanostructured with large nanometer sized $\mathrm{Ag}_{2} \mathrm{Te}$ precipitates there is an enhancement of $z T$ due to phonon scattering at the interfaces. The enhancement in $z T$ resulting from these two mechanisms is of similar magnitude but, in principle, decoupled from one another. This work experimentally demonstrates a successful combination of the complexity in the valence band structure with the addition of nanostructuring to create a high performance thermoelectric material. These effects lead to a high $z T$ over a wide temperature range with peak $z T>1.5$ at $T>650 \mathrm{~K}$ in Na-doped $\mathrm{PbTe} / \mathrm{Ag}_{2} \mathrm{Te}$. This high average $z T$ produces $30 \%$ higher efficiency $(300-750 \mathrm{~K})$ than pure Na-doped $\mathrm{PbTe}$ because of the nanostructures, while the complex valence band structure leads to twice the efficiency as the related $n$-type La-doped $\mathrm{PbTe} / \mathrm{Ag}_{2} \mathrm{Te}$ without such band structure complexity.
\end{abstract}

Thermoelectric (TE) applications have attracted increasing interest in the last decade as a means to combat the ever growing rate of energy consumption throughout the world. The two main applications for thermoelectric materials are power generation, which utilizes the Seebeck effect, and solid state cooling, which has its roots in the Peltier effect. In recent years, thermoelectric power generation has been a prime interest to the automotive industry $^{1}$ as a sustainable and emission free route to vehicular waste heat recovery. The effectiveness of this process is restricted by the overall efficiency of the thermoelectric materials.

On a materials level, the efficiency of the thermal to electrical energy conversion is determined by the thermoelectric figure of

Materials Science, California Institute of Technology, Pasadena, CA, 91125,USA.E-mail: jsnyder@caltech.edu merit, $z T=S^{2} \sigma T /\left(\kappa_{E}+\kappa_{L}\right)$, where $S, \sigma, \kappa_{E}$ and $\kappa_{L}$ are the Seebeck coefficient, electrical conductivity, and the electronic and lattice components of the thermal conductivity. Since $S, \sigma$ and $\kappa_{E}$ have an intimate relationship with the carrier density, ${ }^{1,2}$ the grand challenge in designing thermoelectric materials is the decoupling of electronic and thermal properties. Many methods to achieve a large power factor $\left(S^{2} \sigma\right)$ or to reduce the thermal conductivity were proven to be successful, but combination of these two effects is difficult. As a result, the current best commercially available thermoelectric materials have a peak $z T$ near unity.

A number of mechanisms have been proposed to explain high $z T$ in p-type $\mathrm{PbTe}$. The Tl-doping in $\mathrm{PbTe}: \mathrm{Tl}$ produces resonant electronic states that enhances the Seebeck coefficient, but reduces hole mobility ${ }^{3}$ and has $z T \sim 1.4$ at $500{ }^{\circ} \mathrm{C}$. Na-doped $\mathrm{PbTe}: \mathrm{Na},{ }^{4}$ without resonant states, ${ }^{5,6}$ has similarly high $z T$ that

\section{Broader context}

Thermoelectric generators, which directly convert heat into electricity are being considered for industrial or automotive waste heat recovery. However, the relatively low efficiency of thermoelectric materials has limited their use to niche applications. Effective strategies for high performance thermoelectric materials during the past half-century have depended largely on the reduction of heat conduction by the crystal lattice and recently on the proposed band structure engineering for improvements in the electronic properties. The present study shows the effort of combining these two independent research directions, namely reducing the lattice thermal conductivity by scattering phonons through nanostructuring and improving the electronic properties by exploiting complex band structure, as a route to improve the thermoelectric performance. The addition of $\mathrm{Ag}_{2} \mathrm{Te}$ in $\mathrm{PbTe}$ creates nanosized scattering centers for heat carrying phonons while further $\mathrm{Na}$-doping enables multiple bands for enhanced electronic properties. In this way, an enhancement of $30 \% \sim 100 \%$ on thermoelectric efficiency is achieved as compared with the same material having either multiple bands or nanosized scattering centers alone, enabling a synergistic route in the search of high performance thermoelectric materials and devices. 
can be rationalized to be from the multi valley valence band structure ${ }^{4,7}$ of PbTe (a second valence band exists slightly below the principal valence band). Because of the complicated band structure, heavy and precise doping of the valence band is required to reach the high $z T$ doping level. ${ }^{4}$

Because this influence on the valence band structure is purely an electronic effect, there is good potential to further enhance $z T$ for $\mathrm{PbTe}: \mathrm{Na}$ by reducing the lattice thermal conductivity.

It has been demonstrated in numerous reports that nanostructures in PbTe effectively scatter the long wavelength heat carrying phonons to lower the lattice thermal conductivity. ${ }^{\mathbf{8 - 1 2}}$ This approach led to a peak $z T$ of $1.4 \sim 1.7$ in both p $^{10,13,14}$ and n-type ${ }^{8,15,16}$ PbTe materials.

Attempts to nanostructure $p$-type PbTe:Tl with $\mathrm{TlSbTe}_{2}$ have not led to higher $z T$ because of reduced mobility despite lower thermal conductivity. ${ }^{17}$

Among these reports, $\mathrm{PbTe} / \mathrm{Ag}_{2} \mathrm{Te}$ nanocomposites prepared from an equilibrium precipitation differ because of the relatively large size of the nanoscale $\mathrm{Ag}_{2} \mathrm{Te}$ precipitates and in addition, the resultant composite is an intrinsic semiconductor due to the selfcompensated substitutional and interstitial $\mathrm{Ag}^{+}$pairs. ${ }^{16,18,19}$ The lack of extrinsic dopants enables a direct observation of $\kappa_{L}$-reduction due to the embedded nanostructures ${ }^{16}$ because there is very little contribution to $\kappa$ due to the electrons. Moreover, the large $\mathrm{Ag}_{2} \mathrm{Te}$ nanostructures were found to reduce the $\kappa_{L}$ of $\mathrm{PbTe}$ at high temperatures with an equal or greater effect than those of smaller nanosized particles, ${ }^{16}$ while the small nanoparticles reduce the thermal conductivity better than the large particles at low temperatures.

The $\mathrm{PbTe}$ matrix in the $\mathrm{PbTe} / \mathrm{Ag}_{2} \mathrm{Te}$ nanocomposites can be doped n-type with $\mathrm{La}^{16}$ or excess $\mathrm{Ag}^{19}$ which allows as an independent control of carrier density while maintaining the composite microstructure.

Additionally, introducing embedded $\mathrm{Ag}_{2}$ Te nanoparticles into the matrix may mechanically strengthen these brittle materials ${ }^{20}$ for practical applications.

The present work shows our effort toward Na-doping PbTe/ $\mathrm{Ag}_{2} \mathrm{Te}$ nanocomposites and the resulting thermoelectric properties. The low lattice thermal conductivity due to the $\mathrm{Ag}_{2} \mathrm{Te}$ nanoinclusions and the excellent electronic properties due to the complex valence band structure is combined to result in a $z T>$ 1.5 at high temperatures. Moreover, there are significant improvements in the average $z T$ and thermoelectric efficiency throughout the entire temperature range studied, as compared with analogous materials without nanostructures or band structure complexity, or with small nanostructures.

P-type nanocomposites were obtained by Na-doping (PbTe: $\mathrm{Na} / \mathrm{Ag}_{2} \mathrm{Te}$ ). $\mathrm{PbTe} / \mathrm{Ag}_{2} \mathrm{Te}$ nanocomposites with a composition of $(\mathrm{PbTe})_{0.945}\left(\mathrm{Ag}_{2} \mathrm{Te}\right)_{0.055}$ (Fig.1) were pre-synthesized according the reported method ${ }^{\mathbf{1 6}}$ and subsequently used as the starting material for making $\mathrm{PbTe}: \mathrm{Na} / \mathrm{Ag}_{2}$ Te together with appropriate amounts of $\mathrm{Na}$ and Te metals. The nominal concentration of $\mathrm{Na}$ $\left[\left(\mathrm{Na}_{\mathrm{x}} \mathrm{PbTe}_{1+\mathrm{x}}\right)_{0.945}\left(\mathrm{Ag}_{2} \mathrm{Te}\right)_{0.055}\right]$ is $x=0 \sim 3$ at. $\%$ and the samples for this study were synthesized with the same method used previously; ${ }^{16}$ including sealing, melting (Step 1 in Fig. 1), quenching, annealing (Step 2 followed by Step 3) and hot pressing. Phase components were checked using X-ray diffraction and scanning electron microscopy (SEM) equipped with an energy dispersive spectrometer (EDS).

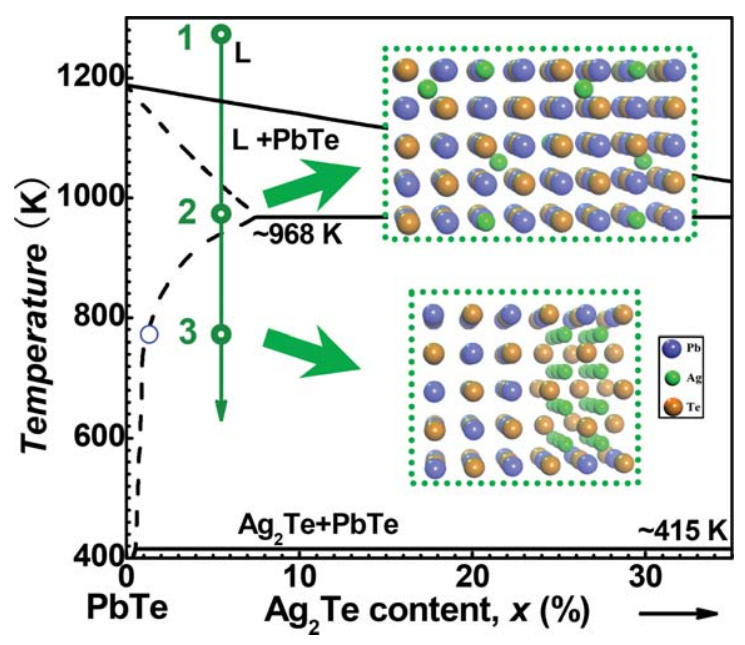

Fig. 1 Phase diagram of PbTe- $\mathrm{Ag}_{2} \mathrm{Te}$ system and the procedure used for material preparation. A low-temperature annealing leads to the precipitation of $\mathrm{Ag}_{2} \mathrm{Te}$ from the high temperature supersaturated alloy phase.

Hot pressed disk-shape samples with relative densities of $98 \%$ or higher were used for the measurements. Details on measuring the transport properties were given elsewhere, ${ }^{4,16}$ where the heat capacity $\left[C_{p}\right.$ in $k_{B}$ per atom $=3.07+4.7 \times 10^{-4} \times$ $(T / \mathrm{K}-300)]^{4,7,19,21}$ was determined by drop calorimetry ${ }^{20}$ and believed to be accurate for several lead chalcogenides. ${ }^{4,22,23}$ The thermal conductivity for most of the recently reported high $z T$ PbTe materials at $600 \sim 800 \mathrm{~K}$, was determined using a heat capacity of, ${ }^{3,16}$ or close to, the Dulong-Petit approximation by $\pm 5 \% .{ }^{10,13,24-26}$ It should be noted that this equation determines a value $\sim 10 \%$ higher than the Dulong-Petit law ( $3 k_{B}$ per atom) at $\mathrm{T}>700 \mathrm{~K}$, and this method is used to recalculate all the literature data used for comparison in this study. The uncertainty for each measurement of $S, \sigma$ and $\kappa$ is $\sim 5 \%$, resulting in a combined error of $\sim 20 \%$ in the determined $z T$ values.

Annealing the high temperature supersaturated solid solution phase (Step 2) of $\mathrm{PbTe} / \mathrm{Ag}_{2} \mathrm{Te}^{27,28}$ in the low temperature, twophase region (Step 3) creates homogenously distributed $\mathrm{Ag}_{2} \mathrm{Te}$ nanoinclusions in a PbTe matrix. ${ }^{16}$ Fig. 2a shows the typical nanostructure for the obtained as-cast ingots. The plate-like $\mathrm{Ag}_{2} \mathrm{Te}$ precipitates have preferred orientation parallel with $<001>$ directions in the PbTe matrix, consistent with previous reports. ${ }^{16,19,29} \mathrm{The} \mathrm{Ag}_{2} \mathrm{Te}$ precipitates are nanometer sized in one direction but micron-size in the other directions, which is larger than those generally observed in $\mathrm{PbTe}_{\mathrm{AgSbTe}}$ and its analogs. ${ }^{9,30} \mathrm{No} \mathrm{Ag}_{2}$ Te precipitates smaller than $\sim 50 \mathrm{~nm}$ could be found in $\mathrm{PbTe} / \mathrm{Ag}_{2} \mathrm{Te}$ system with similar synthesis conditions. ${ }^{16}$

Similar to $\mathrm{PbTe}: \mathrm{Na},{ }^{4} \mathrm{Na}$ is found to be an effective p-type dopant in $\mathrm{PbTe} / \mathrm{Ag}_{2} \mathrm{Te}$ as indicated by the Hall coefficient $\left(R_{H}\right)$ and Seebeck coefficient measurements. However, the doping solubility of $\mathrm{Na}$ in $\mathrm{PbTe} / \mathrm{Ag}_{2} \mathrm{Te}$ is found to be much smaller than in pure $\mathrm{PbTe}$, since the maximum measured room temperature Hall density $\left(p_{H}=1 / e R_{H}, e\right.$ is the electron charge) in PbTe:Na/ $\mathrm{Ag}_{2} \mathrm{Te}$ is much smaller than that in $\mathrm{PbTe}: \mathrm{Na}$, this is presumably due to the presence of a small amount of soluble $\operatorname{Ag}_{2} \mathrm{Te}(\sim 1 \%)^{16}$ in $\mathrm{PbTe}$ matrix reducing the solubility of $\mathrm{Na}$. Even though the nominal concentrations of $\mathrm{Na}$ are comparable in $\mathrm{PbTe}: \mathrm{Na} /$ $\mathrm{Ag}_{2} \mathrm{Te}$ and PbTe:Na, ${ }^{4}$ the measured $p_{H}$ in PbTe: $\mathrm{Na} / \mathrm{Ag}_{2} \mathrm{Te}$ does 
$\mathbf{a}$
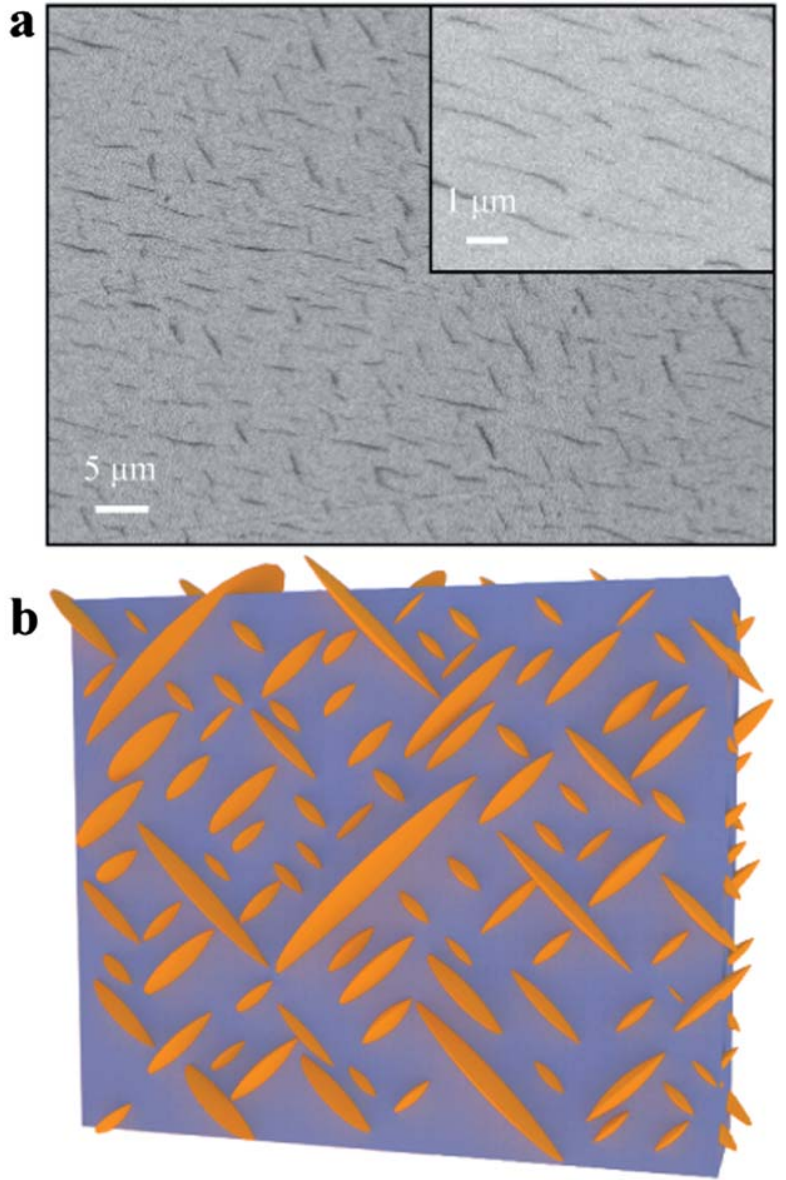

Fig. 2 (a) Typical SEM image of as cast PbTe: $\mathrm{Na} / \mathrm{Ag}_{2} \mathrm{Te}$ ingot. The short plates with a darker contrast indicate the $\mathrm{Ag}_{2} \mathrm{Te}$ phase with different orientations in different grains. The inset is a close up image of the nanostructures indicating the size to be on the order of a few hundred nanometers. (b) A 3D representation of the observed $\mathrm{Ag}_{2} \mathrm{Te}$ (orange) nanostructures embedded in the PbTe matrix (blue).

not exceed $4 \times 10^{19} \mathrm{~cm}^{-3}$, while $p_{H}$ in PbTe:Na can be as high as $14 \times 10^{19} \mathrm{~cm}^{-34}$. Since it was found that the optimal $p_{H}$ was close to $10^{20} \mathrm{~cm}^{-3}$, due to the dominance of the heavy band behavior in $\mathrm{p}-\mathrm{PbTe},{ }^{4}$ the most heavily doped $\mathrm{PbTe}: \mathrm{Na} / \mathrm{Ag}_{2} \mathrm{Te}$ samples with nominal $\mathrm{Na}$ content of $1 \%, 2 \%$ and $3 \%$ having $p_{H}$ of $2.5,3.1$ and $3.7 \times 10^{19} \mathrm{~cm}^{-3}$ are used for the following discussions and marked as 2.5e19, 3.1e19 and 3.7e19, respectively.

As has been well established in $\mathrm{p}-\mathrm{PbTe}$, the room temperature Seebeck coefficient versus Hall density (Pisarenko plot, solid line in Fig. 3a) provides a powerful characterization of the band structure for $\mathrm{PbTe}{ }^{31}$ The majority of published measurements on bulk p-type PbTe fall on this Pisarenko line, as do the present results, within the measurement uncertainty (Fig. 3a). Similar to the findings in La-doped $\mathrm{PbTe} / \mathrm{Ag}_{2} \mathrm{Te}$ (PbTe:La/Ag $\left.2 \mathrm{Te}\right){ }^{16}$ neither doping with $\mathrm{Na}$ nor introducing $\mathrm{Ag}_{2} \mathrm{Te}$ alters the band structure of the $\mathrm{PbTe}$ matrix.

The flattening of $S$ at high doping levels $\left(p_{H}>\sim 3 \times 10^{19} \mathrm{~cm}^{-3}\right)$ can be well understood by the complex valence band structure shown in the inset of Fig. 3a. ${ }^{4,31}$ Furthermore, the energy of the light valence band reduces with increasing temperature and moves below the heavy valence band at $\sim 450 \mathrm{~K},{ }^{31-38}$ making the
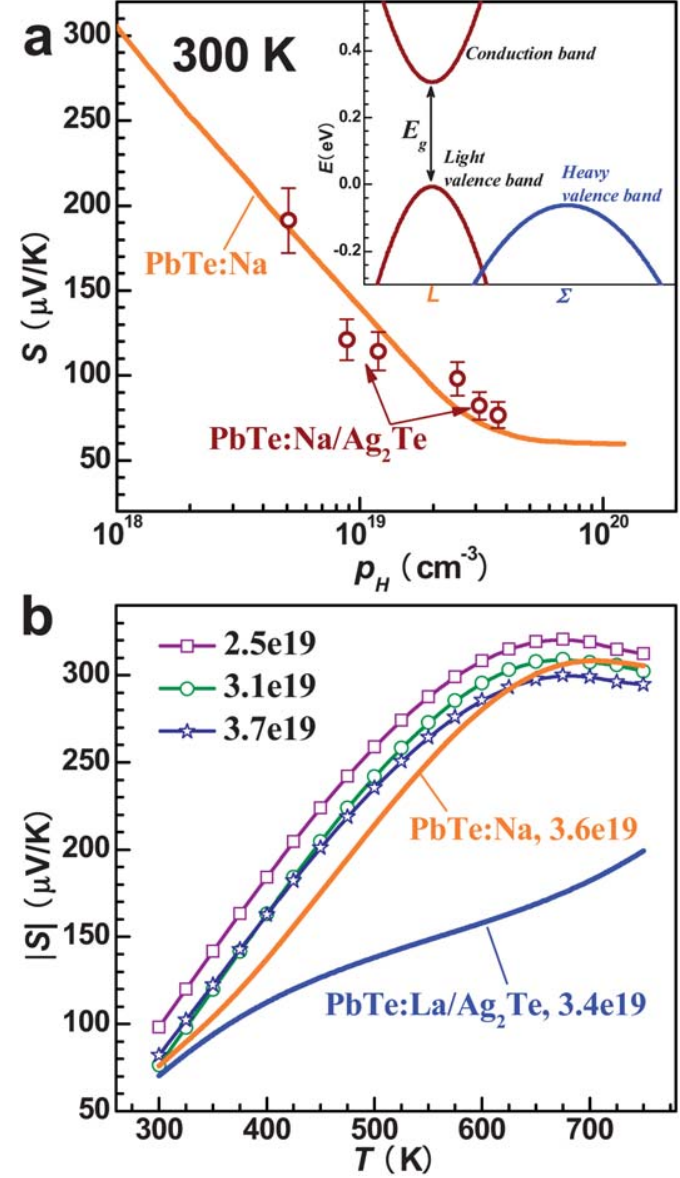

Fig. 3 (a) Room temperature Seebeck coefficient versus Hall density for $\mathrm{PbTe}: \mathrm{Na} / \mathrm{Ag}_{2} \mathrm{Te}$ with an overlaid Pisarenko plot for $\mathrm{PbTe}: \mathrm{Na}$. The inset shows the schematic band structure at $300 \mathrm{~K}$. (b) Temperature dependent Seebeck coefficient along with $\mathrm{PbTe}: \mathrm{Na}$ and n-type $\mathrm{PbTe}: \mathrm{La} / \mathrm{Ag}_{2} \mathrm{Te}$. Complexity of valence band structure significantly increases the Seebeck coefficient.

heavy valence band the dominant band for hole transport at high temperatures where the $z T$ peaks. The electronic transport, optical spectroscopy and other properties of $p$ - $\mathrm{PbTe}$ can be well described by this two-valence-band mode. ${ }^{31-38}$

Rather than the Seebeck coefficient being proportional to absolute temperature (e.g. n-type $\mathrm{PbTe}: \mathrm{La} / \mathrm{Ag}_{2} \mathrm{Te}$ in Fig. 3b), a significant increase in $S$ (Fig. 3b) is observed, particularly at high temperatures, due to the increasing contribution of the heavy band carriers resulting from the temperature dependent band structure and Fermi broadening. The analogous n-type material $\left(\mathrm{PbTe}: \mathrm{La} / \mathrm{Ag}_{2} \mathrm{Te}^{16}\right)$ has a much lower Seebeck coefficient than p-type $\mathrm{PbTe}: \mathrm{Na} / \mathrm{Ag}_{2} \mathrm{Te}$, due to the lack of conduction band complexity. ${ }^{4,31}$ These $\mathrm{PbTe}: \mathrm{Na} / \mathrm{Ag}_{2} \mathrm{Te}$ materials show a roughly unchanged Seebeck coefficient with respect to $\mathrm{PbTe}$ : $\mathrm{Na}$ (without $\mathrm{Ag}_{2} \mathrm{Te}$ ) at similar doping levels, which further supports the above discussion ( $S$ vs. $p_{H}$ ) that $\mathrm{Ag}_{2} \mathrm{Te}$ inclusions do not affect the band structure of $\mathrm{PbTe}$.

While the Seebeck coefficient is similar, the PbTe:Na/Ag $2 \mathrm{Te}$ composites have lower charge carrier mobility compared with $\mathrm{PbTe}: \mathrm{Na}$, due to both the increased scattering of carriers at the phase boundaries and the increased point defect scattering in the 
matrix phase (dilute solid solution of $\mathrm{PbTe}$ with $\sim 1 \% \mathrm{Ag}_{2} \mathrm{Te}^{16,27}$ ). Shown in the inset of Fig. 4 is the Hall mobility $\left(\mu_{H}=R_{H} \sigma\right)$ of PbTe:Na/Ag 2 Te with $p_{H}>\sim 3 \times 10^{19} \mathrm{~cm}^{-3}$ along with a comparison to $\mathrm{PbTe}: \mathrm{Na}$ with similar $p_{H}$. The $\mathrm{PbTe}: \mathrm{Na} / \mathrm{Ag}_{2} \mathrm{Te}$ composites have similar Hall mobility over the entire temperature range, and converge with the $\mathrm{PbTe}: \mathrm{Na}$ sample at high temperatures. This behavior is understood by the scattering of charge carriers in these materials being dominated by acoustic phonons at high temperatures, ${ }^{31}$ while interface and alloy scattering contribute at lower temperatures. As a result, the electrical resistivity of $\mathrm{PbTe}: \mathrm{Na} / \mathrm{Ag}_{2} \mathrm{Te}$ nanocomposites is higher than that of PbTe:Na (Fig. 4) at low temperatures, when the doping levels are nearly the same $\left(p_{H}=3.6 \times 10^{19} \mathrm{~cm}^{-3}\right.$ for PbTe:Na vs. $p_{H}=$ $3.7 \times 10^{19} \mathrm{~cm}^{-3}$ for $\mathrm{PbTe}: \mathrm{Na} / \mathrm{Ag}_{2} \mathrm{Te}$ ). Similar to $\mathrm{PbTe}: \mathrm{Na}^{4}$ (and $\mathrm{n}-\mathrm{PbTe}^{16,31}$ ), the electrical resistivity $(\rho)$ rises faster than normally expected for a system dominated by acoustic scattering $\left(\rho \propto T^{1 \sim 1.5}\right)$. This can be explained by the increasing effective mass of carriers because of the temperature dependent mass of the light bands as well as the transition of holes from the light to the heavy band that has lower mobility. ${ }^{19,31-38}$ Increasing Hall density results in lower electrical resistivity in $\mathrm{PbTe}: \mathrm{Na} / \mathrm{Ag}_{2} \mathrm{Te}$ nanocomposites, as shown in Fig. 4.

The thermal conductivity $(\kappa)$ is reduced by $\sim 50 \%$ in roughly the entire measured temperature range due to the $\mathrm{Ag}_{2} \mathrm{Te}$ nanoinclusions (Fig. 5). It is important to note that the Hall density of all the samples was similar and found to be $\sim 3.5 \times 10^{19} \mathrm{~cm}^{-3}$. To avoid the ambiguity of bipolar thermal conductivity and for the sake of clarity, only heavily doped samples are shown in Fig. 5.

The observed $\kappa$-reduction is only partially attributed to the presence of the nanoinclusions. The reduced electrical conductivity and thus a reduced electronic component to the thermal conductivity $\left(\kappa_{E}\right)$ also contributes to lower $\kappa$. It is difficult to accurately estimate the $\kappa_{E}$ via the Wiedemann-Franz law $\left(\kappa_{E}=\right.$ $L \sigma T)$ because of the difficulty in determining the Lorenz number $(L)$ in $\mathrm{p}-\mathrm{PbTe}$ due to the complex valence band structure and the band non-parabolicity. ${ }^{31,39,40}$ For simplicity, an estimation of $L$ is made using a single parabolic band (SPB) model assuming an

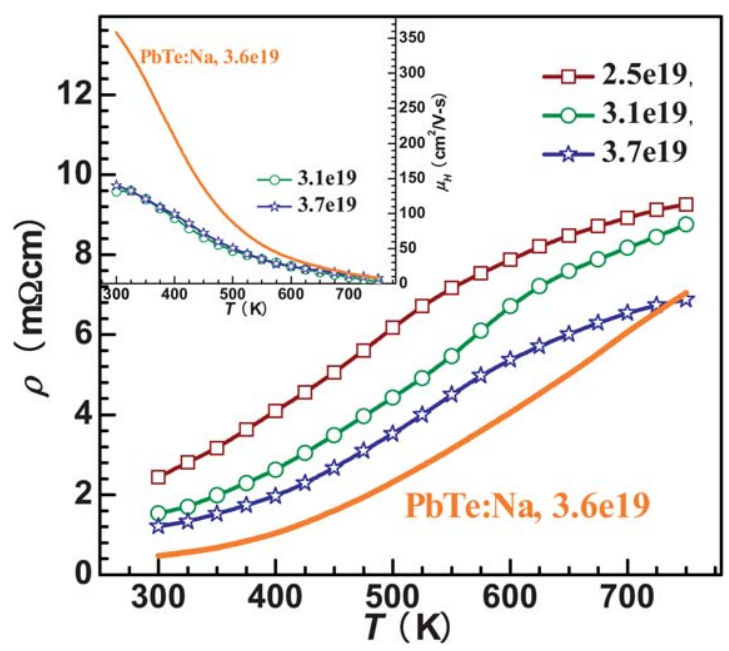

Fig. 4 Temperature dependent electrical resistivity for $\mathrm{PbTe}: \mathrm{Na} / \mathrm{Ag}_{2} \mathrm{Te}$ and $\mathrm{PbTe}: \mathrm{Na}$. $\mathrm{Ag}_{2} \mathrm{Te}$ nanoinclusions simultaneously scatter the carriers thereby reducing the Hall mobility, particularly at low temperatures as shown in the inset.

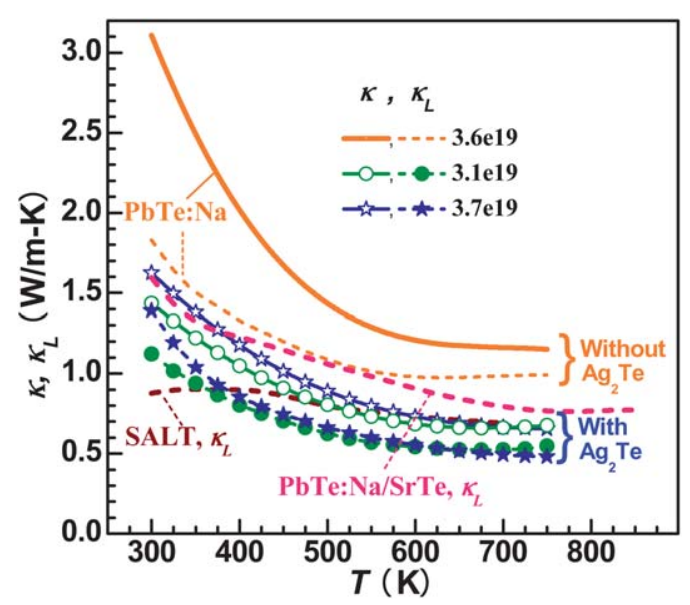

Fig. 5 Temperature dependent thermal conductivity and its lattice component for $\mathrm{PbTe}: \mathrm{Na} / \mathrm{Ag}_{2} \mathrm{Te}$ compared to $\mathrm{PbTe}: \mathrm{Na} .{ }^{4}$ Relatively large $\mathrm{Ag}_{2} \mathrm{Te}$ nanoinclusions effectively scatter phonons thus reducing the lattice thermal conductivity $\left(\kappa_{L}\right)$ to $\sim 0.5 \mathrm{~W} / \mathrm{m}-\mathrm{K}$ at $T>\sim 600 \mathrm{~K}$, well below the value found in high $z T \mathrm{PbTe}: \mathrm{Na} / \mathrm{SrTe}^{10}$ and $\mathrm{PbTe} / \mathrm{NaSbTe}_{2}$ $(\mathrm{SALT})^{13}$ containing smaller nanostructures.

acoustic phonon scattering mechanism, ${ }^{41}$ which results in an $L$ with a deviation of less than $10 \%$ when compared to a more rigorous single non-parabolic band and multiple band model calculation..$^{7,16,39,42}$ And the same method of $L$-estimation is used to recalculate the literature data for the following discussion.

By subtracting the electronic component from the total thermal conductivity, the lattice component $\left(\kappa_{L}\right)$ is calculated and shown in Fig. 5. It can be expected that the introduction of nanoinclusions effectively reduces the lattice thermal conductivity due to the enhanced scattering of phonons at boundaries. ${ }^{8,9,16,19}$ The extremely low $\kappa_{L}$ of $\sim 0.5 \mathrm{~W} / \mathrm{m}-\mathrm{K}$ at $T>600 \mathrm{~K}$ is approaching the theoretical minimum value of $0.36 \mathrm{~W} / \mathrm{m}-\mathrm{K} .{ }^{16,43}$ It should be noted that the total thermal conductivity of $\mathrm{PbTe}$ : $\mathrm{Na} / \mathrm{Ag}_{2} \mathrm{Te}$ composites is significantly lower than the lattice thermal conductivity of $\mathrm{PbTe}: \mathrm{Na}$. As compared with other $\mathrm{PbTe}$ nanocomposites having smaller structure features, such as $\mathrm{PbTe}$ : $\mathrm{Na} / \mathrm{SrTe}^{10}$ and $\mathrm{PbTe} / \mathrm{NaSbTe}_{2}{ }^{13}$ (SALT) and their analogs, where the $\kappa_{L}$ is now recalculated with the same estimation of both $C_{p}$ and $L, \mathrm{PbTe}$ with relatively large $\mathrm{Ag}_{2} \mathrm{Te}$ precipitates has even lower lattice thermal conductivity at high temperatures, similar to that observed in n-type materials. ${ }^{16}$ This is presumably due to at least partial precipitate dissolution of small nanoparticles observed at high temperatures, ${ }^{44}$ while the large $\mathrm{Ag}_{2} \mathrm{Te}$ precipitates in our current and previous study ${ }^{16,19}$ are obtained by annealing at high temperature (Fig. 1) and thus are likely to be more stable.

When compared with n-type La-doping ${ }^{16}$ (using the same estimation of $C_{p}$ ), p-type Na-doping in $\mathrm{PbTe} / \mathrm{Ag}_{2} \mathrm{Te}$ nanocomposites has significantly higher $z T$ (Fig. 6a) at low temperatures because of the favorable electronic effect of the complex band structure. ${ }^{4,7}$ Alternatively, compared with $\mathrm{PbTe}: \mathrm{Na}$ having similar $p_{H}$ of $3.6 \times 10^{19} \mathrm{~cm}^{-3},{ }^{4}$ introducing $\mathrm{Ag}_{2}$ Te nanoinclusions significantly reduces the thermal conductivity (Fig. 5) and thus increases $z T$ (Fig. 6a). This is further evidenced by the excellent agreement between the measured $z T$ of the $\mathrm{PbTe}: \mathrm{Na} / \mathrm{Ag}_{2} \mathrm{Te}$ sample with $p_{H}=3.7 \times 10^{19} \mathrm{~cm}^{-3}$ and the projected $z T$ curve for 

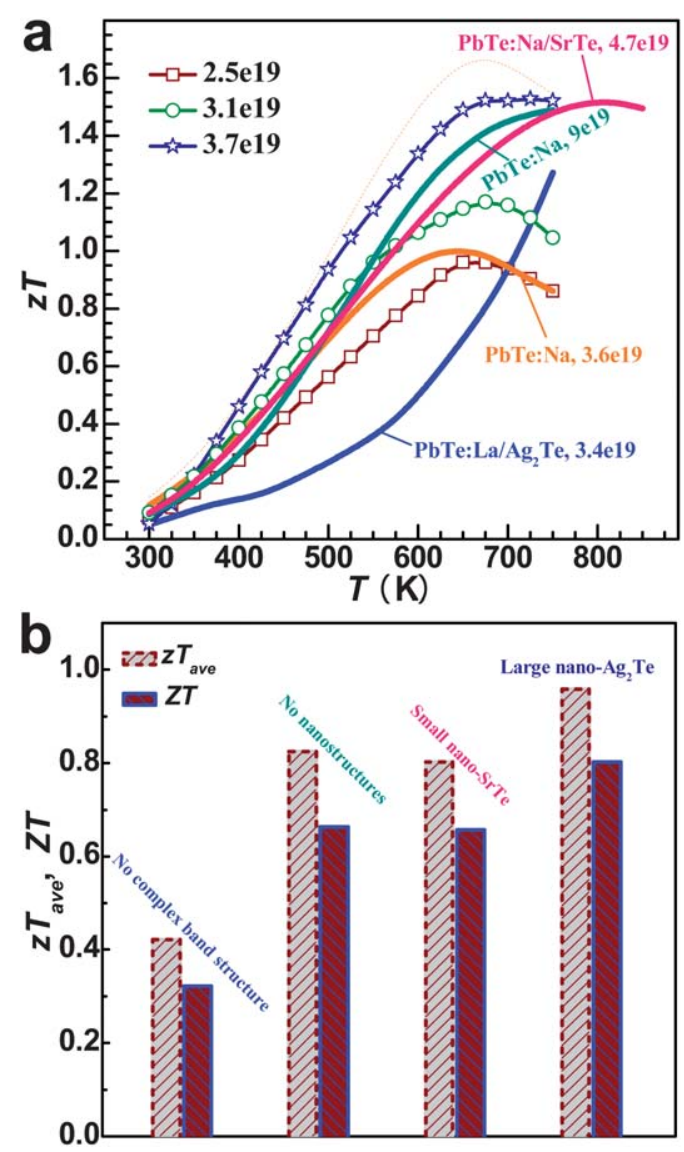

Fig. 6 (a) Temperature dependent thermoelectric figure of merit for PbTe:Na/Ag 2 Te, PbTe:Na, ${ }^{4} \mathrm{PbTe}: \mathrm{La} / \mathrm{Ag}_{2} \mathrm{Te}^{16}$ and $\mathrm{PbTe}: \mathrm{Na} / \mathrm{SrTe} .{ }^{10}$ The improvement in $z T$ is attributed to the reduction of the lattice thermal conductivity in PbTe: $\mathrm{Na}$ (calculated dashed curve). (b) Comparison of the device $Z T$ and the average $z T\left(z T_{\text {ave }}\right)$ from $300-750 \mathrm{~K}$ for PbTe:Na/ $\mathrm{Ag}_{2} \mathrm{Te}, \mathrm{PbTe}: \mathrm{Na},{ }^{4} \mathrm{PbTe}: \mathrm{La} / \mathrm{Ag}_{2} \mathrm{Te}^{16}$ and $\mathrm{PbTe}: \mathrm{Na} / \mathrm{SrTe} .{ }^{10}$ There is roughly a $40-100 \%$ enhancement in both $z T_{\text {ave }}$ and ZT due to the band structure complexity and nanostructuring, when having similar room temperature Hall density of $\sim 3.5 \mathrm{e} 19 \mathrm{~cm}^{-3}$. A $\sim 20 \%$ enhancement on $z T_{\text {ave }}$ and $Z T$ can be also seen when compared with similar materials having small structure features such as $\mathrm{PbTe}: \mathrm{Na} / \mathrm{SrTe} .^{10}$

PbTe:Na with $p_{H}=3.6 \times 10^{19} \mathrm{~cm}^{-3}$ (dashed orange), which is generated by simply assuming the $\kappa_{L}$ value to be that of PbTe: $\mathrm{Na} /$ $\mathrm{Ag}_{2} \mathrm{Te}$ with $p_{H}=3.7 \times 10^{19} \mathrm{~cm}^{-3}$. However, it is unlikely that these materials are fully optimized as the optimal carrier density, as observed in PbTe:Na with $p_{H}=9 \times 10^{19} \mathrm{~cm}^{-3}$ (cyan curve), ${ }^{4}$ was not obtained in this study due to the small dopant solubility.

The current effort of combining both complex band structure and nanostructures enables a $z T$ higher than 1.5 at $T>\sim 650 \mathrm{~K}$. More importantly, as shown in Fig. $6 \mathrm{~b}$, both the average $z T$ $\left(z T_{\text {ave }}\right)$ and the device $Z T$ that is calculated from the theoretically available power generation efficiency $(\eta)^{45-48}$ (between $300 \mathrm{~K}$ and $750 \mathrm{~K}$ ), are found to be enhanced by $40 \sim 100 \%$ in PbTe: $\mathrm{Na} /$ $\mathrm{Ag}_{2} \mathrm{Te}$, when compared to PbTe:La/Ag $\mathrm{Ae}_{2}{ }^{16}$ and PbTe: $\mathrm{Na}^{4}$ having similar $p_{H}$. Here, the estimations of device $Z T$ also take into account the thermoelectric compatibility effect. ${ }^{46-48}$ It should also be note that the $z T_{\text {ave }}$ enables a fairly accurate evaluation of the relative change on the efficiency ${ }^{45}$ even though real device $Z T$ is lower than $z T_{\text {ave }}$ due to the variable compatibility factor. ${ }^{46-48}$ Even though $\mathrm{PbTe}: \mathrm{Na} / \mathrm{Ag}_{2} \mathrm{Te}$ composite is not fully optimized for carrier concentration, $15 \sim 20 \%$ higher $Z T$ and $z T_{a v e}$ have already been achieved as compared with the best PbTe:Na $\left(p_{H}=9 \times 10^{19} \mathrm{~cm}^{-3}\right)^{4}$ and $\mathrm{PbTe}: \mathrm{Na} / \mathrm{SrTe}^{\mathbf{1 0}}$ having smaller and endotaxial nanostructures, indicating the effectiveness of nanostructures for high performance thermoelectrics.

In summary, band structure complexity and nanostructure effects are simultaneously considered as an effective approach for improving thermoelectric performance. These combined approaches have been demonstrated in $\mathrm{PbTe}: \mathrm{Na} / \mathrm{Ag}_{2} \mathrm{Te}$ resulting in a peak $z T$ higher than 1.5 , and more importantly, this results in significant enhancements of the average $z T$ and thermoelectric efficiency. Further study of the combination of carrier density and nanostructure control should result in even higher thermoelectric performance in similar PbTe materials.

The authors gratefully acknowledge NASA-JPL and DARPA for funding support of this work.

\section{References}

1 A. F. Ioffe, Semiconductor thermoelements, and Thermoelectric cooling, Infosearch, London, 1957.

2 G. J. Snyder and E. S. Toberer, Nat. Mater., 2008, 7, 105-114.

3 J. Heremans, V. Jovovic, E. Toberer, A. Saramat, K. Kurosaki, A. Charoenphakdee and G. J. Snyder, Science, 2008, 321, 554-557.

4 Y. Pei, A. LaLonde, S. Iwanaga and G. J. Snyder, Energy Environ. Sci., 2011, 4, 2085-2089.

5 K. Hoang, S. D. Mahanti and M. G. Kanatzidis, Phys. Rev. B: Condens. Matter Mater. Phys., 2010, 81, 115106.

6 S. Ahmad, S. D. Mahanti, K. Hoang and M. G. Kanatzidis, Phys. Rev. B: Condens. Matter Mater. Phys., 2006, 74, 155205.

7 Y. Pei, X. Shi, A. LaLonde, H. Wang, L. Chen and G. J. Snyder, Nature, 2011, 473, 66-69.

8 K. F. Hsu, S. Loo, F. Guo, W. Chen, J. S. Dyck, C. Uher, T. Hogan, E. K. Polychroniadis and M. G. Kanatzidis, Science, 2004, 303, 818821.

9 M. G. Kanatzidis, Chem. Mater., 2010, 22, 648-659.

10 K. Biswas, J. He, Q. Zhang, G. Wang, C. Uher, V. P. Dravid and M. G. Kanatzidis, Nat. Chem., 2011, 3, 160-166.

11 A. Minnich, M. Dresselhaus, Z. Ren and G. Chen, Energy Environ. Sci., 2009, 2, 466-479.

12 J. Baxter, Z. Bian, G. Chen, D. Danielson, M. Dresselhaus and A. Fedorov, Energy Environ. Sci., 2009, 2, 559-588.

13 P. F. P. Poudeu, J. D'Angelo, A. Downey, J. Short, T. Hogan and M. Kanatzidis, Angew. Chem., Int. Ed., 2006, 45, 3835-3839.

14 J. Androulakis, K. F. Hsu, R. Pcionek, H. Kong, C. Uher, J. J. DAngelo, A. Downey, T. Hogan and M. G. Kanatzidis, $A d v$. Mater., 2006, 18, 1170.

15 J. Androulakis, C. H. Lin, H. J. Kong, C. Uher, C. I. Wu, T. Hogan, B. A. Cook, T. Caillat, K. M. Paraskevopoulos and M. G. Kanatzidis, J. Am. Chem. Soc., 2007, 129, 9780-9788.

16 Y. Pei, J. Lensch-Falk, E. S. Toberer, D. L. Medlin and G. J. Snyder, Adv. Funct. Mater., 2011, 21, 241-249.

17 H. Wang, A. Charoenphakdee, K. Kurosaki, S. Yamanaka and G. J. Snyder, Phys. Rev. B: Condens. Matter Mater. Phys., 2011, 83, 024303.

18 A. J. Strauss, J. Electron. Mater., 1973, 2, 553-569.

19 Y. Pei, A. F. May and G. J. Snyder, Adv. Energy Mater., 2011, 1, 291296.

20 E. A. Skrabek and D. S. Trimmer, in CRC handbook of thermoelectrics, ed. D. M. Rowe, CRC Press, Boca Raton, Fla., 1995 , p. 272.

21 H. Wang, Y. Pei, A. D. LaLonde and G. J. Snyder, Adv. Mater., 2011, 23, 1366-1370.

22 R. Blachnik and R. Igel, Z. Naturforsch., B, 1974, 29, 625-629.

23 M. Zhou, J. F. Li and T. Kita, J. Am. Chem. Soc., 2008, 130, 45274532. 
24 P. F. P. Poudeu, A. Gueguen, C. I. Wu, T. Hogan and M. G. Kanatzidis, Chem. Mater., 2010, 22, 1046-1053.

25 K. Ahn, M. K. Han, J. Q. He, J. Androulakis, S. Ballikaya, C. Uher, V. P. Dravid and M. G. Kanatzidis, J. Am. Chem. Soc., 2010, 132, 5227-5235.

26 A. Gueguen, P. F. P. Poudeu, C. P. Li, S. Moses, C. Uher, J. Q. He, V. Dravid, K. A. Paraskevopoulos and M. G. Kanatzidis, Chem. Mater., 2009, 21, 1683-1694.

27 F. Wald, J. Less Common Met., 1967, 13, 579-590.

28 R. Blachnik and B. Gather, J. Less Common Met., 1978, 60, 25-32.

29 J. Lensch-Falk, J. Sugar, M. Hekmaty and D. Medlin, J. Alloys Compd., 2010, 504, 37-44.

30 C. Vineis, A. Shakouri, A. Majumdar and M. Kanatzidis, $A d v$ Mater., 2010, 22, 3970-3980.

31 Y. I. Ravich, B. A. Efimova and I. A. Smirnov, Semiconducting Lead Chalcogenides, Plenum Press, New York, 1970

32 G. Nimtz and B. Schlicht, Springer Tracts in Modern Physics, 1983, 98, 1-117.

33 Y. I. Ravich, in Lead Chalcogenides: Physics and Applications, ed. D. Khokhlov, Taylor \& Fransics Group, New York, 2003, pp. 1-34.

34 R. S. Allgaier, J. Appl. Phys., 1961, 32, 2185-2189.

35 A. J. Crocker and L. M. Rogers, J. Phys. Colloq., 1968, 29, 129-132.

36 V. I. Kaidanov, R. B. Melnik, I. A. Chernik and A. A. Kosulina, Sov. Phys. Semiconductors, 1969, 2, 1474.

37 R. N. Tauber, A. A. Machonis and I. B. Cadoff, J. Appl. Phys., 1966, 37, 4855-4860.
38 J. Androulakis, I. Todorov, D. Y. Chung, S. Ballikaya, G. Y. Wang, C. Uher and M. Kanatzidis, Phys. Rev. B: Condens. Matter Mater. Phys., 2010, 82, 115209.

39 I. A. Smirnov, M. N. Vinogradova, N. V. Kolomoets and L. M. Sysoeva, Sov. Phys. Solid State, 1968, 9, 2074-2079.

40 I. A. Smirnov and Y. I. Ravich, Sov. Phys. Semiconductors, 1967, 1, 739-741.

41 C. M. Bhandari and D. M. Rowe, in CRC handbook of thermoelectrics, ed. D. M. Rowe, CRC Press, Boca Raton, Fla., 1995 , ch. 5, pp. 43-53.

42 S. Ahmad and S. D. Mahanti, Phys. Rev. B: Condens. Matter Mater. Phys., 2010, 81, 165203.

43 Y. K. Koh, C. J. Vineis, S. D. Calawa, M. P. Walsh and D. G. Cahill, Appl. Phys. Lett., 2009, 94, 153101.

44 J. He, J. R. Sootsman, L. Xu, S. Girard, J.-C. Zheng, M. G. Kanatzidis and V. P. Dravid, J. Am. Chem. Soc., 2011, 133, 8786.

$45 \mathrm{R}$. W. Ure and R. R. Heikes, in Thermoelectricity: science and engineering, ed. R. R. Heikes and R. W. Ure, Interscience Publishers, New York, 1961, ch. 15, pp. 458-517.

46 G. J. Snyder, in Thermoelectrics handbook: macro to nano, ed. D. M. Rowe, CRC/Taylor \& Francis, Boca Raton, 2006, ch. 9, pp. 1-26.

47 G. J. Snyder, Appl. Phys. Lett., 2004, 84, 2436-2438.

48 G. J. Snyder and T. Ursell, Phys. Rev. Lett., 2003, 91, 148301 . 